\title{
An experimental meat-free diet maintained haematological characteristics in sprint-racing sled dogs
}

\author{
Wendy Y. Brown ${ }^{1}$, Barbara A. Vanselow ${ }^{2}$, Andrew J. Redman ${ }^{3}$ and John R. Pluske ${ }^{4}$ \\ ${ }^{1}$ Animal Science, School of Environmental and Rural Science, University of New England, Armidale, NSW 2351, Australia \\ ${ }^{2}$ NSW Department of Primary Industries, Beef Industry Centre, University of New England, Armidale, NSW 2351, Australia \\ ${ }^{3}$ Mars Petcare Australia, Petcare Place, Wodonga, Vic 3690, Australia \\ ${ }^{4}$ School of Veterinary and Biomedical Sciences, Animal Research Institute, Murdoch University, Murdoch, WA 6150, Australia \\ (Received 2 December 2008 - Revised 19 April 2009 - Accepted 27 April 2009 - First published online 1 June 2009)
}

A dog's nutrient requirements can theoretically be met from a properly balanced meat-free diet; however, proof for this is lacking. Exercise places additional demands on the body, and dogs fed a meat-free diet may be at increased risk of developing sports anaemia. We hypothesised that exercising dogs would remain in good health and not develop anaemia when fed a nutritionally balanced meat-free diet. To this end, twelve sprint-racing Siberian huskies were fed either a commercial diet recommended for active dogs $(n$ 6), or a meat-free diet formulated to the same nutrient specifications $(n$ 6). The commercial diet contained $43 \%$ poultry meal, whereas soyabean meal and maize gluten made up $43 \%$ of the meat-free diet, as the main protein ingredients. Dogs were fed these diets as their sole nutrient intake for 16 weeks, including 10 weeks of competitive racing. Blood samples were collected at weeks $0,3,8$ and 16 , and veterinary health checks were conducted at weeks 0,8 and 16 . Haematology results for all dogs, irrespective of diet, were within normal range throughout the study and the consulting veterinarian assessed all dogs to be in excellent physical condition. No dogs in the present study developed anaemia. On the contrary, erythrocyte counts and Hb values increased significantly over time $(P<0.01)$ in both groups of dogs. The present study is the first to demonstrate that a carefully balanced meat-free diet can maintain normal haematological values in exercising dogs.

Sled dogs: Exercise: Vegetarian diet: Blood count

There has been a steady increase in the number of articles on vegetarian nutrition in humans appearing in the biomedical literature, and this has been attributed to the increased popularity of vegetarianism ${ }^{(1)}$ and the documented health benefits associated with well-balanced vegetarian diets ${ }^{(2)}$. In contrast to this, there is a dearth of research into vegetarian nutrition in the canine. In this regard, some dog and cat owners wish to feed their pets a totally meat-free diet ${ }^{(3)}$ for the same ethical reasons that they themselves are vegetarian ${ }^{(4)}$. However, none of the currently available meat-free dog and cat foods base their claims of nutritional adequacy on recognised feeding protocols, such as those specified by the Association of American Feed Control Officials (AAFCO) ${ }^{(5)}$. Furthermore, an independent analysis of two commercial vegan diets for cats, claiming to be nutritionally complete and balanced, found the diets to have multiple nutrient deficiencies ${ }^{(6)}$.

Unlike the obligatory carnivorous cat, dogs can synthesise nutrients such as taurine and vitamin $\mathrm{A}^{(7)}$ and theoretically it is possible for the dog to subsist on a diet based solely on plant ingredients. Commercial dry dog foods typically contain a high proportion of plant ingredients, as a high grain content is necessary for successful extrusion ${ }^{(8)}$. It is only a small step from some of the popular cereal-based dry dog foods to one that contains no meat at all. Conceptually, however, the gap is much larger, and demonstrating that a meat-free diet is adequate in sedentary dogs will not change the perception of many dog owners that meat is required for dogs that are actively working, or racing ${ }^{(9)}$. For this reason, sprint-racing sled dogs were chosen for our experiment to challenge the concept that meat is an essential dietary ingredient for exercising dogs. Our aim was to develop a nutritionally adequate meat-free diet, based on chemical analysis, and to demonstrate nutritional adequacy by feeding the diet in a controlled experiment to active dogs. We hypothesised that dogs would remain in good health, based on veterinary health checks and haematological characteristics, and not develop anaemia.

\section{Experimental methods}

Twelve pure-bred Siberian huskies participated in the study, which ran from 24 May to 20 September 2004 to coincide with the Australian sled-dog racing season. The experiment was of 16 weeks' duration, incorporating 2 weeks of prerace training, 10 weeks of competitive racing and 4 weeks of recovery. Throughout the study, dogs were fed either the experimental meat-free diet $(n 6)$ or the meat-based control

Abbreviations: BW, body weight; CP, crude protein; Cr, creatine; ME, metabolisable energy; PCV, packed cell volume.

* Corresponding author: Dr Wendy Yvonne Brown, fax +61 26773 3922, email wbrown@une.edu.au 
diet $(n$ 6) as their sole nutrient intake. Blood samples $(5 \mathrm{ml})$ were collected from the cephalic vein of dogs at rest $(0,3,8$ and 16 weeks) and analysed for complete blood count using an automated cell counter (CellDyn 3500R; Abbott Diagnostics, North Ryde, NSW, Australia). Veterinary health checks were performed at weeks 0,8 and 16 by the dog owners' usual veterinarian, who was blinded to the dietary treatments. Veterinary health checks consisted of a full physical examination, auscultation of the heart and lungs, and measurement of rectal temperatures. Authority to conduct the present study was granted by the University of New England Animal Ethics Committee, in accordance with section 25 of the Animal Research Act (1985).

\section{Animal management}

For the duration of the study, dogs were maintained in their usual environment (Malusky Kennels, Belford, NSW, Australia), kennelled in pairs, with free access to water at all times. Dogs were always kennelled with another dog from the same dietary group to remove any likelihood of dogs accessing the wrong diet. Each dog had its own bed, and kennels were fully covered and protected from the weather. A large outdoor grassed enclosure provided additional social interaction where dogs were placed twice per $d$, as a single group, under the owners' supervision. The temperature in the kennels ranged from $-5^{\circ} \mathrm{C}$ to $27^{\circ} \mathrm{C}$ over the study period.

At 6 weeks before commencing the experiment, dogs were administered booster vaccinations against canine distemper, hepatitis and parvovirus (Canvac ${ }^{\mathrm{TM}} 3$; CSL, Parkville, Vic, Australia) by subcutaneous injection. Dogs were weighed and treated orally with anthelmintic (Drontal ${ }^{\circledR}$ Allwormer ${ }^{\circledR}$; Bayer Australia Ltd, Pymble, NSW, Australia) worming tablets (active ingredients: praziquantel, $50 \mathrm{mg}$; pyrantel embonate, $49.8 \mathrm{mg}$; febantel, $250 \mathrm{mg}$ ) at the recommended dose rate (one tablet per $10 \mathrm{~kg}$ body weight $(\mathrm{BW})$ ) at week 0 and again at week 5 .

\section{Diets and feeding}

Two diets were compared in the present study, a meat-based and a meat-free diet of similar nutrient composition (Tables 1 and 2). The meat-based diet was a commercial dog food recommended for active dogs (Pedigree ${ }^{\circledR}$ Advance $^{\mathrm{TM}}$ Energy - chicken; Mars Petcare Australia, Raglan, NSW,

Table 1. Composition of diets before extrusion

\begin{tabular}{lcc}
\hline & \multicolumn{2}{c}{ Diet } \\
\cline { 2 - 3 } Ingredient (g/kg) & Meat-based & Meat-free \\
\hline Rice (broken) & 120 & 120 \\
Maize (whole) & 170 & 250 \\
Sorghum & 140 & - \\
Poultry meal & 430 & - \\
Maize gluten & 60 & 300 \\
Fine soya meal & - & 130 \\
Sodium caseinate & - & 60 \\
Vegetable mix & - & 60 \\
Sugarbeet pulp & 30 & - \\
Vitamin and mineral mix & 50 & 80 \\
\hline
\end{tabular}

Australia) and contained $43 \%$ poultry meal (before extrusion) as its main protein source. The experimental meat-free diet (manufactured at the Mars Petcare pilot plant, Wodonga, Vic, Australia) contained maize gluten and fine soya meal (passed through a $1 \mathrm{~mm}$ sieve) as its main protein sources, which together made up $43 \%$ of the pre-extrusion ingredients. The meat-free diet was coated with stabilised vegetable oil, whereas the meat-based diet was coated with poultry tallow and poultry digest. A balanced amino acid ratio was achieved in the meat-free diet without the use of crystalline amino acids. Dogs were fed their allocated diets in individual bowls as a single meal each evening, and this comprised their sole nutrient intake for the duration of the 16-week experiment. Dogs were observed during feeding to confirm that each individual consumed its allocated ration. Individual feed intakes were recorded daily and BW were measured fortnightly. Individual feeding levels were adjusted as necessary to maintain ideal BW. Ideal BW were determined by the trainer and equated to a body condition score of 4 using a standard nine-point scale (Purina Body Condition System) ranging from 1 (emaciated) to 9 (severely obese).

As the meat-free diet had not been manufactured previously, a separate feeding trial was conducted to determine digestibility coefficients of the experimental diet. For the digestibility trial, eight dogs of mixed breeds were individually housed on concrete floors at the University of New England Dog Research Facility. Following an adaptation period, the experimental diet was fed solely for $12 \mathrm{~d}$ and all faeces produced during the final $4 \mathrm{~d}$ were collected for determination of total-tract apparent digestibility.

\section{Exercise and racing schedule}

Dogs were trained and raced in teams (a six-dog team, a fourdog team, and a two-dog team) by their usual trainers. Within teams, each dog was paired with another dog of similar ability, based on the trainer's assessment of performance before the commencement of the trial. Each dog was harnessed to its allocated exercise partner for all training and racing activities. Within each exercise pair, one dog was allocated to diet 1 and the other to diet 2, maintaining an even distribution for sex, BW and age between the two dietary groups. Following allocation of dogs into diet groups 1 and 2, the test diets were then arbitrarily designated: the meat-free as diet 1 and meat-based as diet 2. Each group comprised three female and three male dogs; mean age and BW were 3.7 years and $19.7 \mathrm{~kg}$ respectively for dogs fed the meat-free diet and 3.2 years and $20.2 \mathrm{~kg}$ for dogs fed the meat-based diet. One dog from each group was neutered; all others were entire.

Pre-race training commenced with the onset of cooler weather in April, and involved dogs pulling heavily laden carts at slow speed. The final 2 weeks of this phase of training were included in the experiment, during which the dogs completed seven training runs of $6 \mathrm{~km}$ distances at an average speed of $12 \mathrm{~km} / \mathrm{h}$. The next 10 weeks involved competitive racing in addition to the training runs which continued three or four times per week. The heavily weighted rigs were replaced with light-weight rigs, and the training runs became faster $(20 \mathrm{~km} / \mathrm{h})$ and longer $(6-10 \mathrm{~km}$ runs $)$. Dogs participated in sprint races approximately once a fortnight, from 12 June (week 2) until the 14 August (week 12). Sprint races were run in accordance with Australian Sled-dog Sports Association 
Table 2. Analysed chemical composition of diets (as fed) and average daily intakes in twelve Siberian huskies (Mean values and standard deviations for six animals per group)

\begin{tabular}{|c|c|c|c|c|c|c|}
\hline & \multirow{2}{*}{\multicolumn{2}{|c|}{ Content in diet (per kg) }} & \multicolumn{4}{|c|}{ Daily intake (per kg body weight ${ }^{0.75}$ ) } \\
\hline & & & \multicolumn{2}{|c|}{ Meat-based diet } & \multicolumn{2}{|c|}{ Meat-free diet } \\
\hline & Meat-based & Meat-free & Mean & SD & Mean & SD \\
\hline $\mathrm{DM}(\mathrm{g})$ & 927 & 936 & $30 \cdot 36$ & 4.28 & 27.59 & 3.15 \\
\hline Gross energy (MJ) & 20.9 & 21.1 & 0.68 & $0 \cdot 10$ & 0.73 & 0.08 \\
\hline Crude protein (g) & 306 & 289 & $10 \cdot 02$ & 1.41 & $10 \cdot 02$ & $1 \cdot 15$ \\
\hline Crude fat $(\mathrm{g})$ & 166 & 165 & 5.44 & 0.77 & 5.72 & 0.64 \\
\hline Starch $(g)$ & 310 & 296 & $10 \cdot 15$ & 1.43 & $10 \cdot 26$ & $1 \cdot 17$ \\
\hline Free sugars (g) & 7.5 & $19 \cdot 8$ & 0.25 & 0.03 & 0.69 & 0.08 \\
\hline Soluble NSP (g) & 4.6 & 3.6 & 0.15 & 0.02 & 0.13 & 0.01 \\
\hline Insoluble NSP (g) & $29 \cdot 7$ & $38 \cdot 8$ & 0.97 & 0.14 & 1.35 & 0.15 \\
\hline Total NSP (g) & $34 \cdot 3$ & $42 \cdot 4$ & $1 \cdot 12$ & 0.16 & 1.48 & $0 \cdot 17$ \\
\hline
\end{tabular}

(ASSA) rules, the maximum distance for a sprint race being $12 \mathrm{~km}$ for a team of six, $9 \mathrm{~km}$ for a team of four, and $2 \mathrm{~km}$ for a team of two. Following the 10 -week racing phase, training was gradually reduced over the 4-week recovery period.

\section{Chemical analysis of diets}

Representative samples of the two diets were finely ground before chemical analyses. $\mathrm{N}$ content was determined using an FP-2000 LECO Nitrogen Analyzer (LECO Corp., St Joseph, MO, USA), from which crude protein (CP) concentration was calculated $(\mathrm{CP}=\mathrm{N} \times 6 \cdot 25)$. The gross energy of the diets was determined with an IKA ${ }^{\circledR}$-Werke $\mathrm{C} 7000$ bomb calorimeter (IKA ${ }^{\circledR}$ Group, Staufen, Germany). The metabolisable energy (ME) content was calculated from digestible $\mathrm{CP}$ and gross energy using a correction factor of $5023 \mathrm{~kJ} / \mathrm{g}$ for energy lost in urine ${ }^{(5)}$. Fat content was determined by Soxhlet extraction with chloroform ${ }^{(10)}$. Total starch content was determined using the Megazyme Total Starch assay kit (Megazyme Australia Pty, Warriewood, NSW, Australia). The NSP content of the diets was determined by a combination of the methods of Englyst \& Hudson ${ }^{(11)}$ and Theander \& Westerlund ${ }^{(12)}$. Amino acid analysis was conducted by the Department of Primary Industries (Werribee, Vic, Australia). The amino acids, apart from tryptophan, were assayed using cation exchange chromatography following acid hydrolysis. Methionine and cystine were first pre-oxidised with formic acid before acid hydrolysis. Tryptophan was determined by alkaline hydrolysis using a reverse-phase column with UV detection at $280 \mathrm{~nm}$. Mineral content was determined using a Reagent-Free ${ }^{\text {TM }}$ Ion Chromatograph (ICS-2000 Ion Chromatography System; Dionex Corp., Sunnyvale, CA, USA) and AS40 Autosampler (Dionex Corp.).

\section{Statistical methods}

ANOVA for repeated measures was performed on haematological data using the Super ANOVA statistical software package (Abacus Concepts, Berkley, CA, USA). Factors fitted to the model were diet, time and their interaction. Duncan's new multiple-range test was used to separate the means which differed significantly. Data are presented as mean values with their standard errors. Haematological values differed between the dietary groups at the commencement of the study (week 0) for erythrocytes, $\mathrm{Hb}$ and packed cell volume (PCV). To enable interpretation of the effect of diet on these variables, values measured at week 0 for each dog were subtracted from values measured at subsequent weeks and these differences from the initial baseline values were then subjected to statistical analysis.

\section{Results}

Both the meat-based and the meat-free diets were readily consumed. Average daily nutrient intakes are presented in Table 2. Based on chemical analyses, both of the diets fed in the present study exceeded the recommended nutrient requirements for maintenance in adult $\operatorname{dogs}^{(13)}$ (Table 3). All nutrients were within the known minimum and safe maximum upper limits. From the digestibility trial, DM, gross energy, CP and starch digestibility for the meat-free diet were: 83.1 (SEM 0.91), 87.5 (SEM 0.69), 89.4 (SEM 0.61) and 97.7 (SEM 0.11) \% respectively.

Dogs performed well at a national level in races; the six-dog team was placed fourth overall from twenty-nine competitors (dog teams) and the four-dog team finished seventh out of thirty-six competitors in the 2004 Australian Sled-dog Sports Association (ASSA) National Point Scores. Veterinary health checks conducted at weeks 0,8 and 16 found all dogs to be in good health and no abnormalities were detected. Haematology results were consistent with published normal ranges for haematological values for $\operatorname{dogs}{ }^{(14)}$ throughout the study. Erythrocyte counts, $\mathrm{PCV}$ and $\mathrm{Hb}$ concentration increased significantly $(P<0 \cdot 01)$ with time in both groups of dogs (Table 4). There was no significant effect of diet, and no significant interaction between diet and time, on any of the blood characteristics measured in the present study.

\section{Discussion}

Dog foods are tested for their nutritional adequacy in the first instance by means of chemical analysis. However, not all of the nutrients present in the dog food will necessarily be available to the dog. This is why recognised feeding protocols are 
Table 3. Nutrient content of experimental diets and National Research Council (NRC) recommended ${ }^{(13)}$ allowances for maintenance in adult dogs ${ }^{*}$

\begin{tabular}{|c|c|c|c|}
\hline \multirow[b]{2}{*}{ Nutrient } & \multicolumn{2}{|c|}{ Diet } & \multirow[b]{2}{*}{ NRC recommended } \\
\hline & Meat-based & Meat-free & \\
\hline \multirow{2}{*}{\multicolumn{4}{|c|}{ Essential amino acids }} \\
\hline & & & \\
\hline Arginine $(\mathrm{g})$ & 4.53 & 3.65 & 0.88 \\
\hline Histidine (g) & 1.61 & 1.93 & 0.48 \\
\hline Isoleucine (g) & 3.07 & $3 \cdot 16$ & 0.95 \\
\hline Leucine $(\mathrm{g})$ & 7.08 & $8 \cdot 84$ & $1 \cdot 70$ \\
\hline Lysine (g) & 2.55 & $2 \cdot 76$ & 0.88 \\
\hline Methionine (g) & 1.07 & 1.42 & 0.83 \\
\hline Phenylalanine (g) & $3 \cdot 62$ & 4.09 & $1 \cdot 13$ \\
\hline Threonine (g) & 3.02 & $2 \cdot 78$ & 1.08 \\
\hline Tryptophan (g) & 0.50 & 0.55 & 0.35 \\
\hline Valine $(\mathrm{g})$ & $4 \cdot 19$ & 3.88 & 1.23 \\
\hline Crude fat (g) & $41 \cdot 1$ & $40 \cdot 7$ & $13 \cdot 8$ \\
\hline \multicolumn{4}{|l|}{ Minerals } \\
\hline $\mathrm{Ca}(\mathrm{g})$ & 3.5 & $2 \cdot 3$ & 1.0 \\
\hline$P(g)$ & 2.5 & $1 \cdot 7$ & 1.0 \\
\hline $\mathrm{Mg}(\mathrm{g})$ & 0.3 & 0.3 & 0.2 \\
\hline $\mathrm{Na}(\mathrm{g})$ & $2 \cdot 2$ & $2 \cdot 1$ & 0.2 \\
\hline$K(g)$ & 1.6 & 2.9 & 1.0 \\
\hline $\mathrm{Fe}(\mathrm{mg})$ & $53 \cdot 0$ & $30 \cdot 6$ & 7.5 \\
\hline $\mathrm{Cu}(\mathrm{mg})$ & 4.9 & $6 \cdot 0$ & 1.5 \\
\hline $\mathrm{Zn}(\mathrm{mg})$ & $123 \cdot 2$ & $35 \cdot 2$ & $15 \cdot 0$ \\
\hline $\mathrm{Mn}(\mathrm{mg})$ & 3.6 & 5.9 & 1.2 \\
\hline
\end{tabular}

*All values reported are per $4184 \mathrm{~kJ}(1000 \mathrm{kcal})$ metabolisable energy.

used to support nutritional adequacy claims. Where diets are specifically formulated and marketed for active dogs, it would seem that testing these diets in actively exercising dogs would be a more appropriate test of the diet's nutritional adequacy for its designated purpose.

The present study is the first to demonstrate using a short feeding trial that a meat-free diet can be nutritionally adequate for exercising dogs. Whilst longer-term trials are necessary to prove this claim, nutritional adequacy was shown by chemical analyses, and this was further demonstrated by feeding the diet, in a controlled experiment, to actively exercising dogs. Each dog fed the meat-free diet was harnessed to a dog fed the meat-based diet and therefore did exactly the same intensity and amount of exercise. Blood profiles and veterinary examinations indicated that all the dogs remained in good health throughout the study irrespective of whether they were fed diets based on animal or plant proteins. There is only one other study reported in the literature that examines a meat-free diet in exercising dogs and, in that study, dogs fed the vegetable-protein diet developed anaemia (evidenced by a significant decrease in $\mathrm{Hb}$ and erythrocyte counts) whilst dogs fed the animal-protein diet showed no significant haematological changes ${ }^{(15)}$.

Many human vegetarians have achieved prowess as athletes and the nutritional considerations for vegetarian athletes have been well documented ${ }^{(16)}$. Studies reported in the scientific literature have found no differences in fitness or performance between vegetarian and non-vegetarian athletes ${ }^{(17,18)}$ and have concluded that a balanced meat-free diet is not detrimental to athletic performance ${ }^{(19,20)}$. All of the amino acids that are known to be essential for man and for dogs can be obtained from plant sources. However, there appears to be a propensity for human vegetarians to have lower mean muscle creatine (Cr) concentrations than omnivores ${ }^{(21)}$ and as $\mathrm{Cr}$ is an important component of the energy delivery process, it has been suggested that this could affect exercise performance. Supplementing diets with $\mathrm{Cr}$ has been shown to increase exercise potential in humans, and it has been suggested that an adequate supply of dietary $\mathrm{Cr}$ might also be important for exercising dogs. Whilst moderate intakes of $\mathrm{Cr}$ could be expected from consuming raw meat, commercial dog foods provide very little $\mathrm{Cr}$ due to its degradation by heat

Table 4. Changes in blood variables measured in Siberian huskies during a racing season in which dogs were fed either meat-free or meat-based diets as their sole nutrient intake for 16 weeks

(Mean values with their standard errors for six animals per group)

\begin{tabular}{|c|c|c|c|c|c|c|c|}
\hline \multirow[b]{2}{*}{ Variable } & \multicolumn{2}{|c|}{ Meat-based diet } & \multicolumn{2}{|c|}{ Meat-free diet } & \multicolumn{3}{|c|}{$P$} \\
\hline & Mean & SEM & Mean & SEM & Diet & Time & Diet $\times$ time \\
\hline Erythrocyte count $\left(\times 10^{12} / \mathrm{l}\right)^{*}$ & & & & & 0.54 & 0.002 & 0.46 \\
\hline Week 0† & $6 \cdot 52^{\mathrm{a}}$ & 0.27 & $6 \cdot 02^{\mathrm{a}, \mathrm{b}}$ & 0.12 & & & \\
\hline Week 3 & $-0.08^{a}$ & 0.21 & $-0.08^{a}$ & $0 \cdot 18$ & & & \\
\hline Week 8 & $0.47^{\mathrm{b}}$ & 0.34 & $0.28^{\mathrm{a}, \mathrm{b}}$ & 0.25 & & & \\
\hline Week 16 & $0.73^{b}$ & 0.25 & $0.35^{\mathrm{b}}$ & 0.21 & & & \\
\hline $\mathrm{Hb}(\mathrm{g} / \mathrm{l}) \ddagger$ & & & & & 0.66 & 0.006 & 0.81 \\
\hline Week 0† & $150 \cdot 4^{a}$ & $5 \cdot 2$ & $143 \cdot 8^{a, b}$ & $3 \cdot 1$ & & & \\
\hline Week 3 & $-0.8^{a}$ & $4 \cdot 1$ & $-1.9^{a}$ & 3.9 & & & \\
\hline Week 8 & $10 \cdot 3^{b}$ & $6 \cdot 8$ & $5 \cdot 4^{a, b}$ & $5 \cdot 1$ & & & \\
\hline Week 16 & $9 \cdot 4^{b}$ & $5 \cdot 4$ & $7 \cdot 1^{\mathrm{b}}$ & $3 \cdot 4$ & & & \\
\hline Packed cell volume (\%)§ & & & & & 0.73 & 0.01 & 0.71 \\
\hline Week 0† & $43.96^{a}$ & 1.55 & $41 \cdot 85^{a}$ & 0.80 & & & \\
\hline Week 3 & $-0.35^{\mathrm{a}}$ & 1.39 & $-0.10^{a}$ & $1 \cdot 14$ & & & \\
\hline Week 8 & $2.97^{b}$ & $2 \cdot 17$ & $1 \cdot 81^{b}$ & 1.50 & & & \\
\hline Week 16 & $3 \cdot 22^{b}$ & 1.61 & $2 \cdot 14^{b}$ & $1 \cdot 15$ & & & \\
\hline
\end{tabular}

${ }^{a, b}$ Mean values for a variable within a column with unlike superscript letters were significantly different $(P<0.05)$.

* The normal range for erythrocyte count in dogs is 5.5 to $8.5 \times 10^{12} / l$.

† Values measured at week 0 are baseline values. Data presented for weeks 3 to 16 are differences from baseline values.

$\ddagger$ The normal range for $\mathrm{Hb}$ in dogs is 120 to $180 \mathrm{~g} / \mathrm{l}$.

$\S$ The normal range for packed cell volume in dogs is 37 to $55 \%$. 
processing ${ }^{(22)}$. However, it is not essential for mammals to have $\mathrm{Cr}$ in the diet, as it is synthesised in the body from the amino acids arginine and glycine. Based on findings that oral $\mathrm{Cr}$ supplementation did not lead to corresponding increases in muscle concentrations in caged beagles ${ }^{(23)}$ or in racing greyhounds, and that $\mathrm{Cr}$ supplementation in racing greyhounds did not improve performance ${ }^{(24)}$, it is unlikely that a lack of dietary $\mathrm{Cr}$ would have any detrimental effect on exercising dogs, provided that dietary intakes of arginine and glycine are adequate.

Extraordinarily high daily ME intakes $\left(4100 \mathrm{~kJ} / \mathrm{kg} \mathrm{BW}^{075}\right.$ per d) have been recorded in Alaskan sled dogs racing long distances $(490 \mathrm{~km})$ in freezing conditions ${ }^{(25)}$, whereas the sled dogs in the present study raced over short distances in mild climatic conditions. The average daily ME intakes of the sled dogs in our experiment were calculated to be 572 (SEM 71) $\mathrm{kJ} / \mathrm{kg} \mathrm{BW}^{075}$ per $\mathrm{d}$ and this is consistent with $\mathrm{ME}$ requirements reported for moderately active border collies ${ }^{(26)}$.

The haematology results from the present study reveal some interesting findings, but it should be emphasised that all values were always within normal range. It should also be noted that the observed increases in erythrocyte counts, PCV and $\mathrm{Hb}$ were greatest in dogs fed the meat-based diet and that the sample size ( $n$ 6) might have been insufficient to detect significant differences between the two dietary groups. In our experiment, erythrocyte counts and PCV increased significantly over time $(P<0.01)$ in all dogs, whether they were fed the meat-based or the meat-free diet. In contrast to this, both PCV and erythrocytes decreased significantly $(P<0.05)$ over time in twelve sprint-racing Alaskan huskies during a $24-$ week training and racing season ${ }^{(27)}$. The Alaskan huskies were fed diets that contained 20 and $24 \% \mathrm{CP}$ (as fed), which is considerably less than the $\mathrm{CP}$ content of the diets used in the present study (approximately 30\% CP). Another experiment with thirty-two Alaskan sled $\operatorname{dog} \mathrm{s}^{(28)}$ found that PCV and erythrocytes increased after training in dogs fed diets of higher protein content $(3 \cdot 6,5 \cdot 3$ and $6 \cdot 1 \mathrm{~g} / \mathrm{kg} \mathrm{BW}$ per d) but decreased in identically exercised dogs fed the diet with the lowest CP content $(3.0 \mathrm{~g} / \mathrm{kg} \mathrm{BW}$ per d). Dogs in the present study received $4.7 \mathrm{~g} \mathrm{CP} / \mathrm{kg} \mathrm{BW}$ per $\mathrm{d}$, and the increase in PCV and erythrocytes observed in our dogs is consistent with these results. Human studies have shown that exercise increases erythrocyte destruction ${ }^{(29)}$, but provided that this does not exceed erythrocyte production then no detrimental effects occur ${ }^{(30)}$. From the present study, and the work of Reynolds et al. ${ }^{(28)}$, it appears that feeding dogs a higher concentration of protein enabled a higher rate of erythrocyte production, in excess of the numbers destroyed by exercise. These findings highlight the importance of providing sufficient dietary protein for exercising dogs, irrespective of whether the protein is of plant or animal origin.

\section{Conclusions}

The present study is the first to demonstrate the potential for a meat-free diet to be nutritionally adequate for exercising dogs. In a 16-week controlled experiment, a meat-free diet maintained haematological characteristics in sprint-racing sled dogs (Siberian huskies). Importantly, these findings pave the way for commercial pet food manufacturers to produce nutritionally adequate meat-free diets for dogs.

\section{Acknowledgements}

The present study was funded by an Australian Research Council Linkage Grant to which Mars Petcare Australia contributed as the industry partner. The authors would like to thank Anne and Donal McIntyre (Malusky Kennels, Belford, NSW, Australia) for allowing their dogs to participate in the present study, and for their assistance throughout the trial; and Dr Dorothy Robinson of NSW Department of Primary Industries (Beef Industry Centre) for her assistance with the statistical analysis.

An abstract of this research was presented at the 18th Symposium of 'Recent Advances in Animal Nutrition in Australia' (June 2005), University of New England, Armidale, NSW, Australia.

Author contributions were as follows: W. Y. B., canine nutrition, study design and oversight; B. A. V., veterinary haematology; A. J. R., diet formulations; J. R. P., nutrition and physiology.

A. J. R. was employed by Mars Petcare Australia. None of the other authors has any conflicts of interest to declare.

\section{References}

1. Sabate J, Duk A \& Lee CL (1999) Publication trends of vegetarian nutrition articles in biomedical literature, 1966-1995. Am J Clin Nutr 70, 601S-607S.

2. White R \& Frank E (1994) Health effects and prevalence of vegetarianism. West J Med 160, 465-470.

3. Dzanis DA (1999) Vegetarian diets for pets? In FDA Veterinarian Newsletter, vol. XIV, no. III, pp. 3-5. Rockville, MD: FDA Veterinarian, Center for Veterinary Medicine.

4. Wakefield LA, Shofer FS \& Michel KE (2006) Evaluation of cats fed vegetarian diets and attitudes of their caregivers. $J$ Am Vet Med Assoc 229, 70-73.

5. Association of American Feed Control Officials (2007) Official Publication of the Association of Feed Control Officials. Atlanta, GA: Association of American Feed Control Officials Inc.

6. Gray CM, Sellon RK \& Freeman LM (2004) Nutritional adequacy of two vegan diets for cats. J Am Vet Med Assoc 225, 1670-1675.

7. MacDonald ML, Rogers QR \& Morris JG (1984) Nutrition of the domestic cat, a mammalian carnivore. Annu Rev Nutr 4, 521-562.

8. Dzanis D (2003) Petfood types, quality assessment and feeding management. In Petfood Technology, 1st ed., pp. 68 [JL Kvamme and TD Phillips, editors]. Mt Morris, IL: Watt Publishing Co.

9. Griffiths BC (1969) Nutrition of the greyhound. Vet Rec 84, 654-656.

10. Association of Official Analytical Chemists (1995) Official Methods of Analysis, 15th ed. Washington, DC: Association of Official Analytical Chemists.

11. Englyst HN \& Hudson GJ (1993) Dietary fiber and starch: classification and measurement. In Dietary Fiber and Human Nutrition, 2nd ed., pp. 53-71 [G Spiller, editor]. Boca Raton, FL: CRC Press, Inc.

12. Theander O \& Westerlund E (1993) Determination of individual components of dietary fiber. In Dietary Fiber and Human Nutrition, 2nd ed., pp. 77-98 [G Spiller, editor]. Boca Raton, FL: CRC Press, Inc.

13. National Research Council (2006) Nutrient Requirements of Dogs and Cats. Washington, DC: The National Academies Press.

14. Bentinck-Smith J (1980) A roster of normal values for dogs and cats. In Current Veterinary Therapy, 7th ed., 
pp. 1321-1330 [RW Kirk, editor]. Philadelphia, PA: W.B. Saunders Company.

15. Yamada T, Tohori M, Ashida T, et al. (1987) Comparison of effects of vegetable protein diet and animal protein diet on the initiation of anemia during vigorous physical training (sports anemia) in dogs and rats. J Nutr Sci Vitaminol (Tokyo) 33, 129-149.

16. Barr SI \& Rideout CA (2004) Nutritional considerations for vegetarian athletes. Nutrition 20, 696-703.

17. Nieman DC (1988) Vegetarian dietary practices and endurance performance. Am J Clin Nutr 48, 754-761.

18. Hanne N, Dlin R \& Rotstein A (1986) Physical fitness, anthropometric and metabolic parameters in vegetarian athletes. J Sports Med Phys Fitness 26, 180-185.

19. Eisinger M, Plath M, Jung K, et al. (1994) Nutrient intake of endurance runners with ovo-lacto-vegetarian diet and regular Western diet. Z Ernährungswiss 33, 217-229.

20. Nieman DC (1999) Physical fitness and vegetarian diets: is there a relation? Am J Clin Nutr 70, 570S-575S.

21. Venderley AM \& Campbell WW (2006) Vegetarian diets: nutritional considerations for athletes. Sports Med 36, 293-305.

22. Harris RC, Lowe JA, Warnes K, et al. (1997) The concentration of creatine in meat, offal and commercial dog food. Res Vet Sci 62, $58-62$.
23. Lowe JA, Murphy M \& Nash V (1998) Changes in plasma and muscle creatine concentration after increases in supplementary dietary creatine in dogs. J Nutr 128, 2691S-2693S.

24. National Research Council (2006) Physical activity and environment. In Nutrient Requirements of Dogs and Cats, pp. 300-301. Washington, DC: The National Academies Press.

25. Hinchcliff K, Reinhart G, Burr J, et al. (1997) Metabolizable energy intake and sustained energy expenditure of Alaskan sled dogs during heavy exertion in the cold. Am J Vet Res $\mathbf{5 8}$, 1457-1462.

26. Burger IH (1994) Energy needs of companion animals: matching food intakes to requirements throughout the life cycle. J Nutr 124, 2584S-2593S.

27. Querengaesser A, Iben C \& Leibetseder J (1994) Blood changes during training and racing in sled dogs. J Nutr 124, 2760S-2764S.

28. Reynolds A, Reinhart G, Carey D, et al. (1999) Effect of protein intake during training on biochemical and performance variables in sled dogs. Am J Vet Res 60, 789-795.

29. Smith J, Kolbuch-Braddon M, Gillam I, et al. (1995) Changes in the susceptibility of red blood cells to oxidative and osmotic stress following submaximal exercise. Eur J Appl Physiol Occup Physiol 70, 427-436.

30. Smith J (1995) Exercise, training and red blood cell turnover. Sports Med 19, 9-31. 